\title{
Disability competency in social work education: Tools for practice teaching
}

\section{Ami Goulden ${ }^{1}$}

\begin{abstract}
Social work education has been slow at integrating components of disability studies into its curricula, despite increasing prevalence of social work practice with disabled people. The profession has historically ascribed to a medical model of disability and it has struggled with how best to support service users living with disabilities. Social workers' attitudes towards disabled people form an essential component to rapport building and working relationships with persons with disabilities. Most social work graduates encounter disabled people in their practice, so incorporating assessment tools in training and field education may assist educators in evaluating students who will be working with this population. Indeed, ample evidence suggests that field instructors require additional assessment tools for evaluating students' preparedness for the field (Vinton \& Wilke, 2011). This paper has three objectives: 1) to review disability competence within the social work profession in the North American context, 2) to compare the validity, practicality, and theoretical frameworks of two disability attitudinal scales as potential assessment tools for student evaluations, and 3) to offer recommendations for the implication of social work education and practice.
\end{abstract}

Keywords: disability; social work competency; social work assessment; social work education; field education

1. PhD candidate,Factor-Inwentash Faculty of Social Work, University of Toronto.

Address for correspondence: ami.goulden@mail.utoronto.ca

Date of first (online) publication: 29th June 2020

61 J. of Practice Teaching \& Learning 17(2), pp.61-77. @ w\&b 


\section{Introduction}

According to the World Health Organization (WHO) (2011), over one billion people worldwide live with a disability. That number is steadily increasing due to various factors, such as an aging population and a rise in chronic health conditions (WHO, 2011). These factors imply an urgency for improving accessibility and accommodating healthcare services. Traditional healthcare services are often criticized for perpetuating an antiquated medical model of disability, which is an antecedent to their inability to meet the unique and intersectional needs of disabled people (Prilleltensky, 2003; Tarasoff, 2017). Research suggests that disabled people who encounter ableism from service providers have poorer health outcomes (Mitra, Long-Bellil, Smeltzer, \& Iezzoni, 2015; Shpigelman, 2015), increasing the likelihood of negative experiences with the healthcare system. Consequently, social workers' attitudes towards disabled people are related to components of optimal service delivery, and assessment of attitudes is commonly absent from formal curricula and practicum training. The purpose of the current paper is threefold: to review disability competency within the social work profession; to compare the validity, practicality, and theoretical frameworks of the Disability Attitudes in Health Care (DAHC) scale and the Social Worker's Attitudes Toward Disability Scale (SWADS) as potential assessment tools for competency measures; and to offer recommendations for social work practice implications.

\section{Social work competency and disability}

The social work profession has struggled with how to best support disabled people (MacDonald, Carter, Hanes, Skinner, \& McMurphy, 2014; Mackelprang, 2010). At the same time, social work students often consider working with disabled people to be a lower priority compared to those in other fields (Rees \& Raithby, 2012). This suggests a more negative attitude towards the work or even the individuals. Despite this, social workers engage with disabled people in various capacities and settings such as child welfare, schools, healthcare centres, community programs, and mental health organizations. Given the intersectional nature of disability, social workers must be flexible in their approaches to fit the needs of service

62 J. of Practice Teaching \& Learning 17(2), pp.61-77. ๑ wE-b 
users while concurrently using a self-reflecting approach in social work practice (Monahan \& Lurie, 2003). The social work profession has typically embraced individual medicalised understandings of disabled people, rather than using service users' standpoints and knowledge (Beresford $\&$ Boxall, 2012; Mackelprang, 2010). Failure to involve service users in the development of social work practice approaches risks reinforcing oppressive knowledge and negative attitudes about them (Wilson \& Beresford, 2000).

\section{Social work student attitudes towards disabled people}

The individual model of disability, promoted by medical approaches, is arguably the most dominant model when it comes to conceptualizing disability. This model reduces the concept of disability to the flawed tragedy of the individual, inferring that is treatable through charitable and medical interventions (Goodley \& Swartz, 2016; Oliver, 1990). The major foci in this approach are on restoration of bodily functions and overcoming daily limitations (Roulstone, 2012). The individual model translates into social work practice through a deficit-treatment lens. Interventions revolve around the service user's impairment instead of strengths-based and empowerment perspectives (Early \& GlenMaye, 2000; Gilson \& DePoy, 2002). These latter perspectives have widely adopted constructionist approaches to recognizing disability as a socially constructed phenomenon as opposed to the individual model (Mullaly, 2002). The constructionist approach conceptualizes disability as a phenomenon that factors construct, but such factors lay outside of the unique aspects of the individual including physical, behavioural, and cognitive features (Shakespeare \& Watson, 1997). Empowerment and strengths-based perspectives promote a paradigm shift from the old deficit-focused lens to disability as an element of human diversity that is valuable (Gilson \& DePoy, 2002).

Social work students' attitudes towards disabled people are closely related to overarching paradigms and stereotypes that emerge within students' societal contexts and environments. For instance, students may enter social work education with pre-established negative attitudes towards disabled people, and they may later adopt a deficit-treatment lens within their practicum placements. Multiple studies have reported service user collaboration in social work education as a successful approach to challenging students' biases and assumptions regarding the

63 J. of Practice Teaching \& Learning 17(2), pp.61-77. ( $w \mathcal{E} b$ 
persons with disability who are using services. For example, following face-to-face contact with clients and families, social work students lessened their stigmatizing attitudes towards people living in poverty (Driessens, McLaughlin, \& van Doorn, 2016) and towards people with mental health issues (Cabiati \& Raineri, 2016). One longitudinal study in the United Kingdom (UK) examined how service users and family collaboration in social work education impacted Bachelor of Social Work (BSW) students' attitudes towards disabled clients (Rees \& Raithby, 2012). The researchers found that incorporating case study activities that had been designed and delivered in collaboration with clients and their families into the classroom was particularly effective at improving attitudes of social work students.

\section{Disability in social work education}

There has been little leadership and direction from professional social work bodies in Canada and the United States when it comes to promoting a paradigm shift for understanding disability, though there are some exceptions. In 1993, the Canadian Association of Social Work Education (CASWE) founded the 'Persons with Disabilities Caucus' to address the lack of social work education and research relating to persons with disabilities in Canadian social work programs (Carter, Hanes, \& MacDonald, 2012). The CASWE accreditation standards were eventually established from this initiative, including disability as a guiding principle for accreditation of social work education programs within a diversity and social justice framework. The eighth CASWE (2014) guiding principle states,

Standards encourage and support diversity and social justice in all aspects/domains of social work programs. Diversity throughout this document refers to a range of characteristics including, but not limited to: age, colour, culture, disability/non-disability status, ethnic or linguistic origin, gender, health status, heritage, immigration status, geographic origin, race, religious and spiritual beliefs, political orientation, gender and sexual identities, and socioeconomic status. (p. 3)

Similarly, the Council on Social Work Education (CSWE) in the United States has made efforts to shift its disability paradigm to a social model much like some initiatives in the UK (Carter, Hanes, \& MacDonald, 2012). The organization has likewise encompassed disability in its diversity framework within its competencies (CSWE, 2015). Even so, disability remains absent from several other Canadian and American professional

64 J. of Practice Teaching \& Learning 17(2), pp.61-77. (C) wEb 
bodies. For example, it is not mentioned in either the Code of Ethics of the National Association of Social Workers (NASW, 2017) or the Canadian Association of Social Workers' (CASW) Code of Ethics (CASW, 2005). The CASW Code of Ethics alludes to disability with the term 'abilities.' The preamble states, 'social workers do not tolerate discrimination based on age, abilities, ethnic background, gender, language, marital status, national status, national ancestry, political affiliation, race, religion, sexual orientation or socio-economic status' (p. 3). There is ongoing discussion and recommendations within social work regarding how to address current practice challenges with disabled people (Meinert, 2010; Rothman, 2010; Stainton, Chenowest, \& Bigby, 2010).

North American social work programs are shifting their curriculum focus to prioritize competency-based education and practice competencies assessment (Regehr, Bogo, Donovan, Lim, \& Regehr, 2012). Field education has traditionally been the primary indicator of students' clinical skills and competencies, and it has featured heavily in formally assessing students. The purpose of field education is to integrate the theoretical and conceptual elements of the academic setting with hands-on practice. Accordingly, field education is a requirement of most undergraduate and graduate social work programs (CSWE, 2015). The CSWE annual survey of social work programs in the United States found there were 518 undergraduate programs and 255 graduate programs in the country in 2017 (CSWE, 2018). The total number of students who attended field practice settings totalled over 60,000 . While this experience is prevalent, field education structures and opportunities vary by social work program-sometimes significantly. For instance, some social work programs offer fields of practice specializations such as addictions, health, or mental health, and others offer methods of specializations such as program evaluation, policy practice, and clinical or direct practice (CSWE, 2018).

Field education student assessment in North American schools of social work largely reflect CSWE competencies as a means of translating academic learning into social work practice (Tapp, Macke, \& McLendon, 2012). Student assessment approaches in field education are unique and depend on the social work program. Typically, field education student assessment involves contributions from the student, field educators, and the program's field liaison, and assessment approaches examples include competency rating scales, reflective journals, essays or written assignments, workbooks, presentations, field observations, and supervision logs (Hay \& O'Donoghue, 2009; Pack, 2014). A variety of assessment strategies

65 J. of Practice Teaching \& Learning 17(2), pp.61-77. @ w\&b 
contribute to overall assessment outcomes (Hay \& O'Donoghue, 2009).

With an increasing competency-driven pedagogy, standardized measurements act as a valuable tool to work towards competency and accreditation goals while ensuring that students are optimizing their learning opportunities. Similar initiatives have been underway for areaspecific competencies in social work such as macro social work (Regehr et al., 2012), social justice practice (Windsor, Shorkey, \& Battle, 2015), and general social work practice (Bogo, Regehr, Hughes, Power, \& Globerman, 2002). Standardized instruments are tools that one can incorporate into a comprehensive assessment of a student during field education.

\section{Competency measures for social work practice with disabled people}

Negative attitudes towards disability act as a barrier that limits access and inclusion to healthcare, education, employment, and leisure for disabled people (Palad et al., 2016). Researchers have developed standardized instruments that measure attitudes toward disabled people in the context of several professions: healthcare workers (Chadd \& Pangilinan, 2011), social workers (Cheatham, Abell, \& Kim, 2015), the general population (Morin, Crocker, Beaulieu-Bergeron, \& Caron, 2013; Power \& Green, 2010; Scior \& Furnham, 2011), educational professionals in higher education (Martín \& Arregui, 2013), and support care staff (Williams \& Rose, 2007). Palad and colleague's (2016) review details the instruments measuring attitudes towards disability.

The purpose of the current section of this paper is to review relevant instruments that assist in assessing social work students and practitioners in both education and practice. The current study located relevant instruments that were developed as assessment tools to measure service provider attitudes towards disabled people by searching the OVID (MEDLINE, EMBASE, and Social Work Abstracts) and ProQuest (PsycINFO, Social Service Abstracts, ERIC, and Sociological Abstracts) databases (February 2018). As parameters for the searches, the author set source and document types as scholarly journals and article, and language was set to English. The keywords and phrases used in the OVID search were (attitude*) AND (disab*) AND (scale) AND (social work) and the ProQuest search strategy

66 J. of Practice Teaching \& Learning 17(2), pp.61-77. ๑ wE-b 
was ab(attitude*) AND (disab*) AND ab(scale) AND (social work). In addition, there was hand searching using reference lists and key journals. Through these search methods, the current study identified 83 results, of which 24 were excluded due to duplication and an additional 52 were excluded because they did not refer to the development and validation of an original scale. Out of the seven remaining, the study excluded three instruments because they were outside of North America (Holler \& Werner, 2018) and professional contexts (Brown et al., 2009; Findler, Vilchinsky, \& Werner, 2007); two were excluded because they failed to measure attitudinal constructs (Guyward et al., 2012; Hall, Dollard, \& Coward, 2010). The two remaining instruments were the Disability Attitudes in Health Care Scale (DAHC) (Chadd \& Pangilinan, 2011) and the Social Worker's Attitudes Toward Disability Scale (SWADS) (Cheatham et al., 2015).

Social workers appear to have limited involvement in developing and implementing competency measures for disability education apart from the SWADS (Cheatham et al., 2015) and their limited contributions to the DAHC (Chadd \& Pangilinan, 2011). Both instruments have similar goals: to assess current attitudes in the field, stimulate discussion around disability issues, and promote culturally competent curricula and practice. The objective of the following section is to review the two instruments by identifying some strengths and weaknesses, as well as to discuss ways to integrate these tools into social work field education and practice assessments.

\section{The Disability Attitudes in Health Care Scale}

Drs. Chadd and Pangilinan developed the DAHC in 2011 at the University of Michigan's Department of Physical Medicine and Rehabilitation with the goal of assessing attitudes held towards disabled people with concern to any professional or student practicing in a healthcare setting. The DAHC is based on two existing and validated scales: the University of California Los Angeles Geriatric Attitudinal Survey (UCLA-GAS) (Reuben et al., 1998) and the Maxwell-Sullivan Attitude Scale (MSAS) (Maxwell \& Sullivan, 1980). While developing the DAHC, Chadd and Pangilinan revised both the UCLA-GAS and MSAS to prioritize attitudes towards working with disabled people. For example, they modified wording in the UCLA-GAS from 'elderly patients' to 'patients with disability.'

67 J. of Practice Teaching \& Learning 17(2), pp.61-77. @ w\&b 
The DAHC is a practical and user-friendly tool. For example, there are no training requirements for administration nor is it time consuming for professionals or students to complete. The scale consists of 17 items on a 5-point Likert scale ranging from 1 (strongly disagree) to 5 (strongly agree). An example of an item is 'people with disabilities are pleasant to be with.' There is no cut-off score; scores can range from 17 to 85 with higher scores indicating a more positive attitude towards disabled people.

The researchers who developed the DAHC recruited a sample of medical students from the University of Michigan $(n=121)$ to test the shared covariance among the items (internal consistency and reliability) in the scale-it was poor to minimally acceptable $(\alpha=0.74)$. The researchers did not calculate interrater and test-retest reliability. They obtained face and content validity by the consensus and item selection of psychiatrists, rehabilitation psychologists, and social workers, but the number of professionals involved is unknown. Chadd and Pangilinan used a third measure, the Attitudes Towards Disabled Persons (ATDP) scale, to evaluate convergent validity (construct validity). Twenty-eight medical interns completed both the ATDP and DAHC, resulting in a fair Pearson correlation coefficient $(r=0.54)$. They also calculated concurrent validity (criterion-related validity) by looking at the relationship between the scores of men versus women using multiple linear regression. Their comprehensive literature review suggested that women are more likely to have a more positive attitude towards disabled people. This was consistent and statistically significant with the results $(p=0.03)$. However, several other predictors were surprisingly insignificant, such as previous experience caring for a person with a disability $(p=0.18)$.

\section{The Social Worker's Attitudes Toward Disability Scale}

The SWADS was developed in 2015 by two social work doctoral candidates, Cheatham and Kim in conjunction with Dr. Abell at Florida State University. Their article on the development and validation of the scale won an honorable mention at the 2016 Journal of Social Work Education awards in the United States. The scale's purpose is to measure social workers' attitudes towards disabled people. The SWADS and DAHC share a similar format. SWADS consists of 27 items on a 7-point Likert scale ranging from 1 (strongly disagree) to 7 (strongly agree). Some items require reverse coding to determine the overall score. Scores range from

J. of Practice Teaching \& Learning 17(2), pp.61-77. @ wE-b 
27 to 189 with higher scores representing more positive attitudes towards disabled people. The scale is divided into three subscales to reflect the core domains of attitude: cognition, feelings, and practice. Scores can be calculated in two ways: as an overall total score or individually for each subscale. The subscale structure is based on the Multidimensional Attitudes Scale Toward Persons with Disabilities (MAS), which has already been validated (Findler et al., 2007). The SWADS is practical and userfriendly, considering there are no training requirements for administrating it and it is not time consuming to complete. An example of a cognition item is, 'I can learn a lot from my clients with disabilities.'

Similar to the DAHC development, the SWADS' creators did not perform test-retest or interrater reliability analyses. Instead, they assessed internal reliability using coefficient alpha and a purposive sample of undergraduate and graduate students attending social work courses at a Southeastern University $(n=237)$ in the United States. Following the internal reliability assessment, the researchers revised the scale to remove eight items concluding alpha coefficients for feelings ( $\alpha=0.85)$, practice $(\alpha=0.862)$, and cognition $(\alpha=0.714)$, with feelings and practice each in respectable ranges. The authors used multiple approaches to assess content validity. During the process, they also reviewed the National Association of Social Workers Code of Ethics and the Americans with Disabilities Act (1990) for content applicable to the three subscales. For further validation, they consulted a panel of six experts from the faculty at the university who assessed the items and provided feedback.

In developing the SWADS, the researchers provided two additional standardized scales, the MAS and Rosenberg's Self-Esteem Scale (RSES) (Rosenberg, 1965), to the sample of students to test for convergent validity. SWADS was correlated with corresponding subscales of the MAS testing the same attitude construct $(r=-.381, p<.001)$. The correlation was negative because higher scores on the MAS indicated negative attitudes towards disabled people. The RSES helped the researchers measure convergent validity-they chose to do this because the literature review suggested positive associations between self-esteem and positive attitudes of disabled people (Garske, 1996, 2002; Livneh, 1982 as cited in Cheatham et al., 2015, p. 385). Similar to the DAHC, the developers hypothesized that the sex of the social worker and previous work experience with disabled people would be positively correlated with positive attitudes (concurrent validity). However, in the final results the social worker's sex was not statistically significant, while previous work experience with disabled

69 J. of Practice Teaching \& Learning 17(2), pp.61-77. ( $w \mathcal{E} b$ 
people was $(p<.001)$. Moreover, the researchers used race and ethnicity to test discriminant validity because no prior studies had shown a correlation between race and ethnicity with attitudes towards disabled people. Race and ethnicity were not statistically significant on a global scale $(p=.09)$ or on the subscales.

\section{Measurement tools in practice}

Both the SWADS and DAHC are relatively new scales that were published within the last ten years. Although some evidence suggests the DAHC's effectiveness in practice, there have been no subsequently published articles that use the SWADS in practice. The DAHC has been cited in two studies that describe it as a measurement tool. The most recent study was conducted at the University of Michigan and compared attitudes towards disabled people between first- and third-year physical therapy doctoral students ( $n=110$ ) (Yorke, Ruediger, \& Voltenburg, 2017). Samples from both the DAHC and ATDP were collected and a Pearson correlation coefficient of $r=0.342(p<.001)$ was calculated for the two scales; this was smaller than the original sample of medical students $(r=0.54)$. The second study was conducted with a sample of medical students at Thomas Jefferson University in Philadelphia and it used a mixed-methods approach to compare control $(n=251)$ and intervention groups $(n=237)$ (Bu, Veloski, $\&$ Ankam, 2016). The study offered no further reliability or validity testing for the DAHC scale. Rather, it used multiple linear regression to examine the effect of the intervention (2.5-hour curriculum) using DAHC scores after controlling for other variables such as students' sex. There was a statistically significant increase in the DAHC score among students who completed the intervention $(p<.001)$. In the study, thematic analysis of open-ended questions supplemented the quantitative findings.

\section{Strengths and limitations of the SWADS and DAHC}

Researchers developed the SWADS and DAHC for examining attitudes of professionals in healthcare, which one might compare with the ATDP, which was designed for assessing those attitudes in the general population. The SWADS and DAHC were tested for reliability and validity, but DAHC

70 J. of Practice Teaching \& Learning 17(2), pp.61-77. ๑ wE-b 
correlation coefficients were less satisfactory than SWADS. One major limitation identified for both scales is that few studies have used them to supplement the original findings with new tests of reliability and validity; however, this is common for newly developed scales. A second limitation for both scales is the sample population they each used. The DAHC is meant for all healthcare professionals, but its sample population was comprised of only medical students from one institution as a testing sample, though a multidisciplinary approach was used in testing content validity (for example, psychiatrists, social workers). The authors were also concerned with self-selection bias due a low response rate (20\%). This was not a limitation for the SWADS because it was designed for social workers, but the fact remains that there were no practitioners actually included in the study.

In terms of the definition of disability itself, there was a disparity in the two scales between how the developers conceptualized disability. The DAHC used a definition of disability common to the individual model, which focuses on impairment. The DAHC scale includes physical disability, but it excludes visual, hearing, and cognitive disabilities from its definition. Comparatively, the SWADS' definition of disability stems from the social model of disability endorsed by the United Nation's Convention on the Rights of Persons with Disabilities (UN, 2007). It includes all disabilities and recognizes the role of the environment in disability. Due to sentiments among professionals and disabled people that the medical model alone is antiquated and inadequate, there is a strong need for further examination of how the DAHC may impact participants' attitudes of disability itself.

Lastly but most importantly, both scales lack expertise and consultation from disabled people. The authors of the SWADS identified this as a limitation. As service users become more engaged in research and education, initiatives to improve social work practice with disabled people should reflect partnerships with disabled people themselves.

\section{Implications for social work education}

Given the design, strengths, and weaknesses of both scales, the SWADS scale appears most appropriate to complement pre-existing social work education. This is owed to the integration of the social model of disability

71 J. of Practice Teaching \& Learning 17(2), pp.61-77. @ w w b b 
in its design and social work students being used during the validation process. The SWADS scale may be particularly useful during field education. For instance, a study in the United States explored leniency bias in evaluation outcomes among field instructors of social work graduate students (Vinton \& Wilke, 2011). The field instructors completed two evaluation ratings of knowledge, values, and skills on the same student: one face-to-face and one anonymously. The results suggest differences between the two ratings, where anonymous measures had lower mean ratings than face-to-face ratings with the students. An implication of this for practice was that field instructors needed freedom to use a range of ratings and methods to evaluate their students. The SWADS may be a useful tool from this perspective, and it may be effective for complementing a number of evaluation methods that field instructors use.

\section{Conclusion}

Support services should promote anti-oppressive and accessible practices free of ableist and negative attitudes towards disabled people. Social workers practice in a multitude of settings with disabled people, which means their attitudes towards disabled people are integral to building therapeutic rapport and working relationships among individuals. Field education is an optimal opportunity to explore and address students' pre-existing attitudes and biases towards disabled people, yet field instructors encounter several challenges during evaluation. One of these challenges is a general lack of well-known assessment tools. This paper reviewed instruments that may complement field education evaluation methods concerning social work students working with disabled people. Its researchers developed the SWADS to evaluate social workers' attitudes towards disability, and they evaluated it using a sample of social work students. The social model of disability being used in the SWADS' design makes it a unique contribution to other assessment tools available. Nonetheless, it is important to note that there are few examples of the SWADS actually being used in practice. Learning how to incorporate a scale is likely to pose some new challenges for field instructors. As field instructors and social work programs determine how to evaluate and assess students in field education, instruments could be a helpful tool used in concert with other qualitative approaches.

72 J. of Practice Teaching \& Learning 17(2), pp.61-77. ๑ wE-b 


\section{References}

Americans with Disabilities Act of 1990, Pub. L. No. 101-336, 104 Stat. 328 (1990) Beresford, P., and Boxall, K. (2012) Service users, social work education and knowledge for social work practice. Social Work Education, 31, 2, 155-167

Bogo, M., Regehr, C., Hughes, J., Power, R., and Globerman, J. (2002) Evaluating a measure of student field performance in direct service. Journal of Social Work Education, 38, 3, 385-401

Brown, T., Mu, K., Peyton, C. G., Rodger, S., Stagnitti, K., Hutton, E., Casey, J., Watson, C., Hong, C.S., Huang, Y.H., and Wu, C. (2009) Occupational therapy students' attitudes towards individuals with disabilities: A comparison between Australia, Taiwan, the United Kingdom, and the United States. Research in Developmental Disabilities, 30, 6, 1541-1555

$\mathrm{Bu}$, P., Veloski, J. J., and Ankam, N. S. (2016) Effects of a brief curricular intervention on medical students' attitudes toward people with disabilities in healthcare settings: American Journal of Physical Medicine and Rehabilitation, 95, 12, 939-945

Cabiati, E., and Raineri, M. L. (2016) Learning from service users' involvement: A research about changing stigmatizing attitudes in social work students. Social Work Education, 35, 8, 982-996

Carter, I., Hanes, R., and MacDonald, J. E. (2012) The inaccessible road not taken: The trials, tribulations and successes of disability inclusion within social work post-secondary education. Canadian Journal of Disability Studies, 1, 1, 109-142

Canadian Association of Social Workers (CASW) (2005) Code of Ethics 2005. Retrieved from https://casw-acts.ca/sites/casw-acts.ca/files/documents/ casw_code_of_ethics.pdf

Canadian Association for Social Work Education (CASWE) (2014) Standards for accreditation. Retrieved from https://caswe-acfts.ca/wp-content/ uploads/2013/03/CASWE-ACFTS.Standards-11-2014-1.pdf

Chadd, E. H., and Pangilinan, P. H. (2011) Disability attitudes in health care: A new scale instrument. American Journal of Physical Medicine and Rehabilitation, $90,1,47-54$

Cheatham, L. P., Abell, N., and Kim, H. (2015) Development and validation of the social worker's attitudes toward disability scale. Journal of Social Work Education, 51, 2, 379-397

Council on Social Work Education (CSWE) (2015) Education policy and accreditation standards. Retrieved from https://www.cswe.org/getattachment/ Accreditation/Accreditation-Process/2015-EPAS/2015EPAS_Web_FINAL. pdf.aspx

73 J. of Practice Teaching \& Learning 17(2), pp.61-77. @ w\&b 
Council on Social Work Education (CSWE) (2018) 2018 statistics on social work education in the United States: Summary of the CSWE annual survey of social work programs. Retrieved from https://cswe.org/getattachment/ Research-Statistics/Annual-Program-Study/2018-Statistics-on-Social-WorkEducation-in-the-United-States.pdf.aspx

Driessens, K., McLaughlin, H., and Doorn, L. van. (2016) The meaningful involvement of service users in social work education: Examples from Belgium and The Netherlands. Social Work Education, 35, 7, 739-751

Early, T. J., and GlenMaye, L. F. (2000) Valuing families: Social work practice with families from a strengths perspective. Social Work, 45, 2, 118-130

Findler, L., Vilchinsky, N., and Werner, S. (2007) The multidimensional attitudes scale toward persons with disabilities (MAS) : Construction and validation. Rehabilitation Counseling Bulletin, 50, 3, 166-176

Garske, G. G. (1996) The relationship of self-esteem to attitudes of personal attendants toward persons with disabilities. Journal of Applied Rehabilitation Counseling, 27, 3-6

Garske, G. G. (2002) Rehabilitation counselor self-reported levels of job satisfaction, self- esteem, and attitudes toward persons with disabilities. Journal of Applied Rehabilitation Counseling, 33, 3-6

Gilson, S. F., and DePoy, E. (2002) Theoretical approaches to disability content in social work education. Journal of Social Work Education, 38, 1, 153-165

Goodley D., and Swartz, L. (2016) The place of disability. in S. Grech, and K. Soldatic (Eds.) Disability in the Global South. International perspectives on social policy administration and practice (pp. 69-83) Springer

Guyard, A., Michelsen, S. I., Arnaud, C., Lyons, A., Cans, C., and Fauconnier, J. (2012) Measuring the concept of impact of childhood disability on parents: Validation of a multidimensional measurement in a cerebral palsy population. Research in Developmental Disabilities, 33, 5, 1594-1604

Hall, G. B., Dollard, M. F., and Coward, J. (2010) Psychosocial safety climate: Development of the PSC-12. International Journal of Stress Management, 17, 4, 353-383

Hay, K., and O'Donoghue, K. (2009) Assessing social work field education: Towards standardising fieldwork assessment in New Zealand. Social Work Education, 28, 1, 42-53

Holler, R., and Werner, S. (2018) Perceptions towards disability among social work students in Israel: Development and validation of a new scale. Health and Social Care in the Community, 26, 3, 423-432

MacDonald, J., Carter, I., Hanes, R., Skinner, S., and McMurphy, S. (2014) Disability and social work education in the United Kingdom. Canadian Journal

74 J. of Practice Teaching \& Learning 17(2), pp.61-77. (C) wEb 
of Disability Studies, 3, 3, 53-82

Mackelprang, R. W. (2010) Disability controversies: Past, present, and future. Journal of Social Work in Disability and Rehabilitation, 9, 2, 87-98

Martín, A., and Arregui, E. (2013) Development and validation of a scale to identify attitudes towards disability in higher education. Psicothema, 25, 3, 370-376

Maxwell, A. J., and Sullivan, N. (1980) Attitudes toward the geriatric patient among family practice residents. Journal of the American Geriatrics Society, $28,8,341-345$

Meinert, R. (2010) Controversies and disputes in disability and rehabilitation. Journal of Socia Work in Disability and Rehabilitation, 9, 2, 69-72

Mitra, M., Long-Bellil, L., Smeltzer, S., and Iezzoni, L. (2015) A perinatal health framework for women with physical disabilities. Disability and Health Journal, 8, 4, 499-506

Monahan, K., and Lurie, A. (2003) Disabled women sexually abused in childhood: Treatment considerations. Clinical Social Work Journal, 31, 4, 407-418

Morin, D., Crocker, A. G., Beaulieu-Bergeron, R., and Caron, J. (2013) Validation of the attitudes toward intellectual disability-ATTID questionnaire. Journal of Intellectual Disability Research, 57, 3, 268-278

Mullaly, R. P. (2002) Challenging oppression: A critical social work approach. Oxford University Press

National Association of Social Workers (NASW) (2017) Code of Ethics of the National Association of Social Workers. Retrieved from https://socialwork. utexas.edu/dl/files/academic-programs/other/nasw-code-of-ethics.pdf

Oliver, M. (1990) The individual and social models of disability. Paper presented at Joint Workshop of the Living Options Group and the Research Unit of the Royal College of Physicians, Thames, UK

Pack, M. (2014) Practice journeys: Using online reflective journals in social work fieldwork education. Reflective Practice, 15, 3, 404-412

Palad, Y. Y., Barquia, R. B., Domingo, H. C., Flores, C. K., Padilla, L. I., and Ramel, J. M. D. (2016) Scoping review of instruments measuring attitudes toward disability. Disability and Health Journal, 9, 3, 354-374

Power, M. J., and Green, A. M. (2010) The attitudes to disability scale (ADS) : Development and psychometric properties. Journal of Intellectual Disability Research, 54, 9, 860-874

Prilleltensky, O. (2003) A ramp to motherhood: The experiences of mothers with physical disabilities. Sexuality and Disability, 21, 1, 21-47

Rees, J., and Raithby, M. (2012) Increasingly strange bedfellows? An examination of the inclusion of disability issues in university- and agency-based social

75 J. of Practice Teaching \& Learning 17(2), pp.61-77. @ w\&bb 
work education in a Welsh context. Social Work Education, 31, 2, 184-201

Regehr, C., Bogo, M., Donovan, K., Lim, A., and Regehr, G. (2012) Evaluating a scale to measure student competencies in macro social work practice. Journal of Social Service Research, 38, 1, 100-109

Reuben, D. B., Lee, M., Davis, J. W., Eslami, M. S., Osterweil, D. G., Melchiore, S., and

Weintraub, N. T. (1998) Development and validation of a geriatrics attitudes scale for primary care residents. Journal of the American Geriatrics Society, 46, $11,1425-1430$

Rosenberg, M. (1965) Society and the adolescent self-image. Princeton University Press

Rothman, J. (2010) The challenge of disability and access: Reconceptualizing the role of the medical model. Journal of Social Work in Disability and Rehabilitation, 9, 2, 194-222

Roulstone, A. (2012) "Stuck in the middle with you': Towards enabling social work with disabled people.' Social Work Education, 31, 2, 142-154

Scior, K., and Furnham, A. (2011) Development and validation of the intellectual disability literacy scale for assessment of knowledge, beliefs and attitudes to intellectual disability. Research in Developmental Disabilities, 32, 5, 1530-1541

Shakespeare, T., and Watson, N. (1997) Defending the social model. Disability and Society, 12, 2, 293-300

Shpigelman, C. (2015) How to support the needs of mothers with physical disabilities? Disability and Rehabilitation, 37, 11, 928-935

Stainton, T., Chenoweth, L., and Bigby, C. (2010) Social work and disability: An uneasy relationship. Australian Social Work, 63, 1, 1-3

Tapp, K., Macke, C., and McLendon, T. (2012) Assessing student performance in field education. Field Educator, 2, 2, 1-14

Tarasoff, L. (2017) 'We don't know. We've never had anybody like you before': Barriers to perinatal care for women with physical disabilities. Disability and Health Journal, 10, 3, 426-433

UN General Assembly, Convention on the Rights of Persons with Disabilities: Resolution / adopted by the General Assembly, 24 January 2007, A/ RES/61/106. Retrieved from http://www.refworld.org/docid/45f973632.html

Vinton, L., and Wilke, D. J. (2011) Leniency bias in evaluating clinical social work student interns. Clinical Social Work Journal, 39, 3, 288-295

Williams, R.J., and Rose, J.L. (2007) The development of a questionnaire to assess the perceptions of care staff towards people with intellectual disabilities who display challenging behaviour. Journal of Intellectual Disabilities, 11, 12, 197-211 Wilson, A., and Beresford, P. (2000) 'Anti-oppressive practice': Emancipation or

76 J. of Practice Teaching \& Learning 17(2), pp.61-77. ๑ wE-b 
appropriation? British Journal of Social Work, 30, 5, 553-573

Windsor, L. C., Shorkey, C., and Battle, D. (2015) Measuring student learning in social justice courses: The diversity and oppression scale. Journal of Social Work Education, 51, 1, 58-71

World Health Organization (WHO) (2011) World report on disability. WHO Library Cataloguing-in-Publication Data. Retrieved from http://www.who.int/ disabilities/world_report/2011/report.pdf

Yorke, A., Ruediger, T., and Voltenburg, N. (2017) Doctor of physical therapy students' attitudes towards people with disabilities: A descriptive study. Journal of Disability and Rehabilitation, 39, 1, 91-97 